\title{
Urgences
}

\section{Je parle de choses lointaines... (traduction de Manon Bibeau)}

\section{Jorge Etcheverry}

Numéro 9, 1er trimestre 1984

URI : https://id.erudit.org/iderudit/025139ar

DOI : https://doi.org/10.7202/025139ar

Aller au sommaire du numéro

Éditeur(s)

Urgences

ISSN

0226-9554 (imprimé)

1927-3924 (numérique)

Découvrir la revue

Citer ce document

Etcheverry, J. (1984). Je parle de choses lointaines... (traduction de Manon

Bibeau). Urgences, (9), 65-68. https://doi.org/10.7202/025139ar d'utilisation que vous pouvez consulter en ligne.

https://apropos.erudit.org/fr/usagers/politique-dutilisation/ 


\section{JORGE ETCHEVERRY}

(Traduction: Manon Bibeau) 
Je parle de choses lointaines. Mais je dois voir et entendre les furieuses objections s'entrecroiser dans I'air comme une bande de chauves-souris folles-comme un essaim d'abeilles dans un ciel avocat

nous pouvons seulement toucher l'angle des choses avec ce langage rapide. Laissons plier nos cordes vocales devant votre appel. Allons droit au but. 


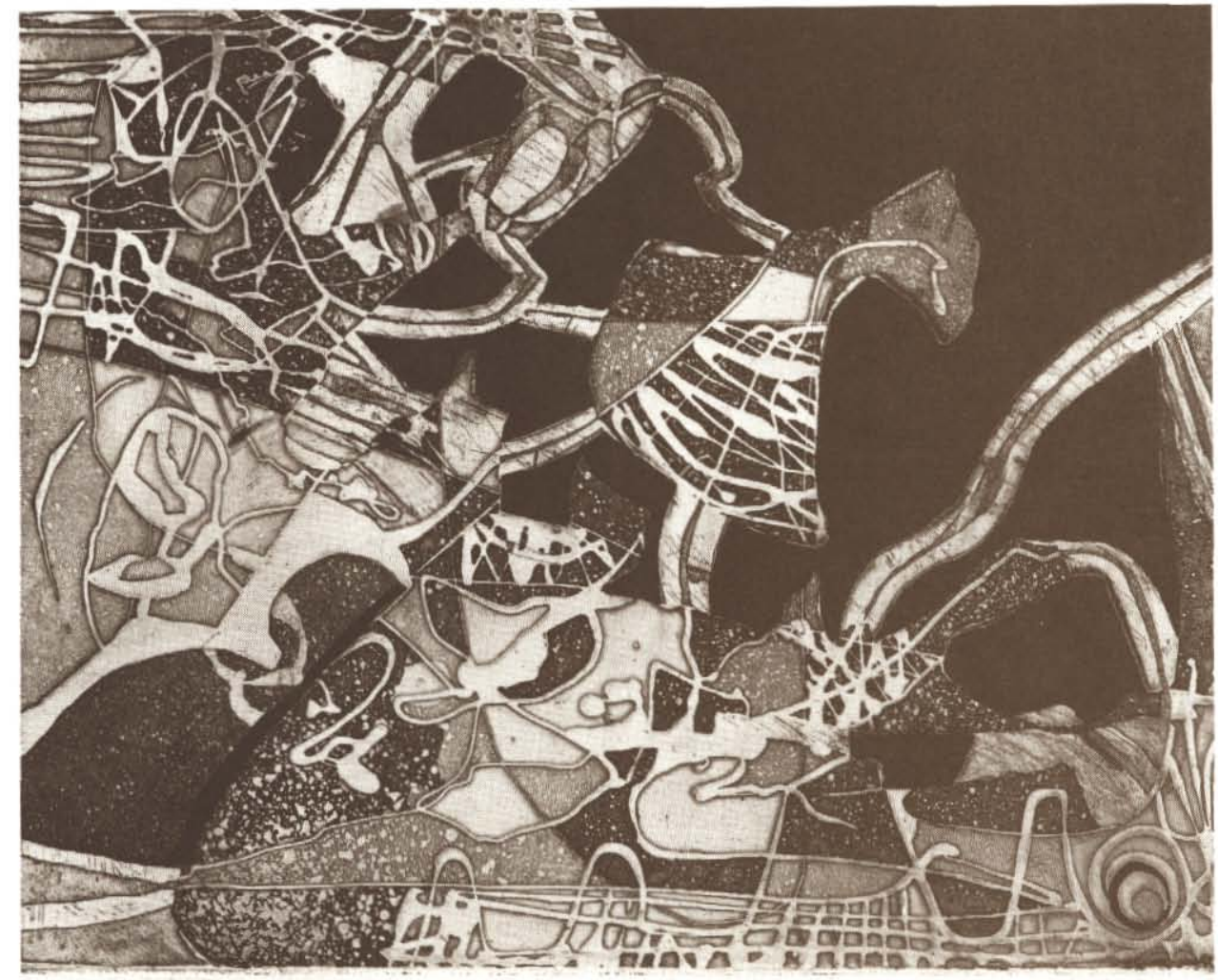


Les citrons changent leur verte robe parmi les feuilles des citronniers-écoute: Douze couples de lunes ne tourneront pas en vain cette fois. Une enfant au bord des larmes tarit l'angle de l'oeil-bleu comme le ciel, vert comme les eaux mortes du marais

Les femelles aux yeux de feu s'étirent dans des lits de soufre à côté d'hommes aux squelettes de pierre. Ouvre les yeux rougis devant I'Immense Disque Solaire, agitateur de chevaux membrus sur les rivages de mers opaques.

Maintenant il nous raconte sa jeunesse. II nous parle de fardeaux portés sur des épaules auparavant dépouillées, maintenant recouvertes d'une sale callosité: Ne t'attarde pas parmi les dormeurs qui tombent dans les champs de chicorée, qui sentent contre leur flanc la rosée qui incline la tête des mauvaises herbes. Face au rêve nous devons nous tenir en hochant la tête autour de feux de joie. Nous avons tiré au sort une grande partie de la nuit, en éloignant le souvenir des contrées humides, de rêve. Plus tard il dit "Les anges ne dorment pas". Les citrons chantent, chuchotent, dans la verte robe des citronniers. Une enfant pleure en silence. Elle tourne la tête. Elle semt I'herbe humide, son iris est le ciel des contrées humides. Le vieillard parcourt le flanc des montagnes, les vertes dépressions et les chemins rouges. II ne parle jamais de ses propres rêves, de chevaux rouges et de femmes aux yeux de feu, immobiles par de sombres nuits chaudes.

Les adorateurs du soleil s'accroupissent, à I'aube, ils couvrent les feux avec de la terre froide, presque congelée. Ils dirigent leurs yeux vers le disque rouge et brûlant. Ils dirigent leurs yeux rougis, tandis que les vrais anges suscitent de justes guerres dans le coeur des hommes, sans craindre le rêve. 